\title{
Effect of coronary occlusion on left ventricular function with and without collateral supply during beating heart coronary artery surgery
}

\author{
T W Koh, G S Carr-White, A C DeSouza, F D Ferdinand, J R Pepper, D G Gibson
}

\begin{abstract}
Objective-To study the effects of coronary occlusion and collateral supply on left ventricular (LV) function during beating heart coronary artery surgery.

Design-Prospective intraoperative study, performed at baseline, during wall stabilisation, coronary artery occlusion, and 2 and 10 minutes after reperfusion. Transoesophageal $M$ mode echocardiograms, simultaneous high fidelity $\mathrm{LV}$ pressure, and thermodilution cardiac output were measured. LV anterior wall thickening, thinning velocities, thickening fraction, regional work, and power production were derived. Asynchrony during the isovolumic periods was quantified as cycle efficiency.
\end{abstract}

Setting-Tertiary referral cardiac centre. Patients-14 patients with stable angina, mean (SD) age 62 (7) years, undergoing left anterior descending artery grafting using the "Octopus" device.

Results-Collaterals were absent in nine patients and present in five. Epicardial stabilisation did not affect $L V$ function. Results are expressed as mean (SD). Coronary occlusion (15.6 (2) minutes) depressed anterior wall thickening (1.4 (0.6) $v 2.6(0.6) \mathrm{cm} / \mathrm{s})$ and thinning velocities (1.4 (0.5) $v 3.0(0.6) \mathrm{cm} / \mathrm{s})$, regional work $\left(2.2(0.8) v 4.6(0.6) \mathrm{mJ} / \mathrm{cm}^{2}\right)$, and power (21 (4) $v 33(5) \mathrm{mW} / \mathrm{cm}^{2}$ ) in patients without collaterals ( $p<0.05$ for all), but only wall thinning $(3.5(0.5)$ v $4.8(0.5) \mathrm{cm} / \mathrm{s}$, $\mathbf{p}<0.05)$ in patients with collaterals. All returned to baseline within 10 minutes of reperfusion. Cycle efficiency and regional work were impaired at baseline and fell during occlusion, regardless of collaterals. Within 10 minutes of reperfusion both had increased above baseline.

Conclusions-Coronary occlusion for up to 15 minutes during beating heart coronary artery surgery depressed standard measurements of systolic and diastolic anterior wall function in patients without collaterals, but only those of diastolic function in patients with collaterals. Regional synchrony decreased in both groups. All disturbances regressed within 10 minutes of reperfusion. (Heart 1999;81:285-291)

Keywords: beating heart coronary artery surgery; left ventricular function; synchrony
Coronary artery bypass grafting on the beating heart was originally performed out of necessity in the 1960 s, because techniques in cardiopulmonary bypass and cardioplegia were yet to be fully established. ${ }^{1}$ Recently, there has been a resurgence in interest in performing coronary artery surgery on the beating heart, ${ }^{23}$ driven partly by the detrimental effects of cardiopulmonary bypass, especially on cerebral function, ${ }^{4}$ and partly by the availability of instruments and drugs which make it possible. ${ }^{5}$ However, regardless of the technique used, a period of coronary artery occlusion is necessary to enable grafting of the coronary vessel in a bloodless field. Indeed, during the course of beating heart surgery, the heart is subjected to ischaemia without any form of myocardial protection for periods that far exceed that seen in other coronary therapeutic procedures, such as percutaneous transluminal coronary angiooplasty (PTCA). The effect of such ischaemia on regional left ventricular (LV) function, and the time course of its recovery, is uncertain. We have therefore performed an intraoperative study to quantify possible disturbances of regional myocardial work, power production, and coordination ${ }^{67}$ during coronary artery occlusion, and to assess the influence of collateral arterial supply and the time course of recovery of these variables, in patients with chronic stable angina undergoing grafting of the left anterior descending artery during beating heart surgery.

\section{Patients and methods}

PATIENTS

We studied 14 patients (mean (SD) age 62 (7) years; $11 \mathrm{men}$ ) undergoing coronary artery surgery without cardiopulmonary bypass using the "Octopus" myocardial stabilisation device. All had chronic stable angina, and stenoses of greater than $70 \%$ in the left anterior descending artery (range 80-99\%), which was grafted with a pedicled left internal mammary artery. Severity of vessel stenosis was independently assessed by the referring cardiologist not involved with the study from semiquantitative visual estimation. In five patients, the right coronary artery was also stenosed and grafted with reversed saphenous vein, following grafting of the left anterior descending artery. Mean (SD) LV ejection fraction measured by contrast angiography in the right anterior oblique view was $60(7) \%$. Coronary angiograms were reviewed and collateral vessels to the left anterior descending artery were graded according to the classification reported by Rentrop et $a l^{8}$ :
Accepted for publication 24 September 1998 


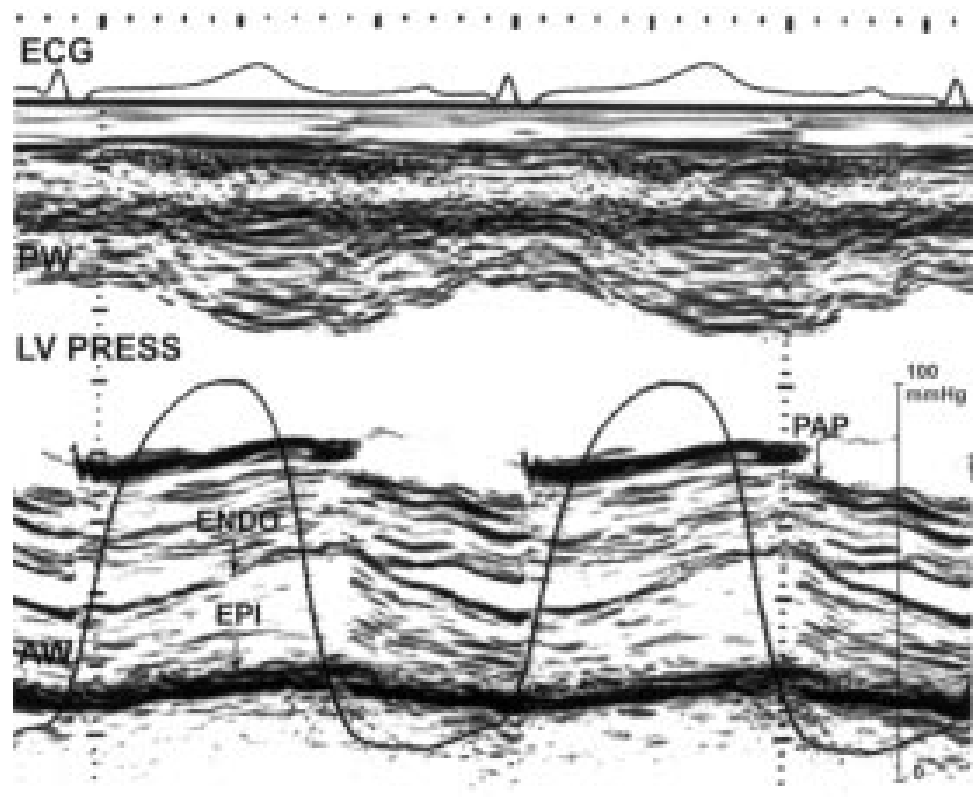

Figure 1 Transoesophageal $M$ mode echocardiogram of the left ventricle in short axis showing the anterior wall and $L V$ pressure recorded simultaneously in a patient undergoing beating heart coronary artery surgery. $A W$, anterior wall; $P W$, posterior wall; $L V$ press, left ventricular pressure trace; END, endocardium; EPI, epicardium; PAP, papillary muscle.

grade 0 , no filling of collateral vessels; grade 1 , filling of collateral vessel without any epicardial filling; grade 2, partial epicardial filling; grade 3 , complete epicardial filling. Nine patients had no visible collateral vessels (grade 0 ) to the left anterior descending artery (no collaterals), while five patients had collateral vessels (grade 2 and 3 ) filling the epicardial vessel (collaterals present). No patient had evidence of previous myocardial infarction either on ECG or from wall motion abnormalities on echocardiography. The protocol was approved by the ethics committee of the Royal Brompton Hospital and written informed consent was obtained from all patients. There were no complications during the study.

OPERATIVE PROCEDURE

General anaesthesia was induced by etomidate, fentanyl, and pancuronium administered intravenously, and maintained by inhaled enflurane according to a standardised protocol. The operation was performed through a median sternotomy. After harvesting the bypass conduits, heparin was given at a dose of $1.0 \mathrm{mg} / \mathrm{kg}$. The "Octopus" device (Medtronic Inc, Grand Rapids, Michigan, USA) consists of two paddles with suction cups on the underside. ${ }^{9-12}$ After opening the pericardium, these were placed on the epicardial surface on either side of the coronary artery to be grafted. The device is attached to the operating table by an articulating arm. The distal segment of the arm is malleable to allow precise positioning of the "Octopus" paddles on the surface of the heart before the arm is tightly fixed on the operating table rail. A suction pump (Eschmann VP12-S, Sussex, UK) was connected to the paddles, and adjusted to apply suction at $500-700 \mathrm{~mm} \mathrm{Hg}$ to the epicardial surface, thereby immobilising the region on either side of the coronary artery. Sutures ( $2 / 0$ prolene) were used as snares to occlude coronary flow proximal and distal to the site of anastomosis to allow grafting of the artery in a bloodless field. When the anastomosis was complete, the coronary snares were released to restore coronary blood flow.

\section{PROTOCOL}

A $5 \mathrm{MHz}$ multiplane transoesophageal probe was inserted after induction of anaesthesia and connected to a Hewlett Packard Sonos 2500 echocardiographic system. The ECG was monitored with the V5 chest lead. Cardiac output was measured by thermodilution with a catheter in the pulmonary artery. After opening the pericardium a $4 \mathrm{~F}$ catheter tip manometer was introduced into the LV cavity via the roof of the left atrium and its output filtered $(1 \mathrm{KHz})$ preamplified, and transferred to the auxiliary channel of the echocardiographic system. The pressure transducer was calibrated electrically before the initial measurement and was checked against an air operated dead weight balance (Budenberg Gauge Company, Altringham, Cheshire, UK) after the study. The zero point for pressure measurement was taken as atmospheric.

A transoesophageal transgastric view of the LV cavity in transverse section was obtained, and $\mathrm{M}$ mode recordings of the LV cavity at papillary muscle level made simultaneously with LV pressure trace (fig 1$).{ }^{13}$ All recordings were made at a paper speed of $100 \mathrm{~mm} / \mathrm{s}$, when the patient was in a stable condition at the following times: after sternotomy (baseline); during myocardial stabilisation using the "Octopus" device; coronary artery occlusion; and 2 and 10 minutes after release of the coronary snare. At the end of the study, the catheter tip manometer was removed, and the exit site at the roof of the left atrium closed with a purse string suture.

The endocardial and epicardial boundaries of the anterior and posterior wall of the $\mathrm{M}$ mode echograms were digitised offline together with the LV pressure trace. The digitising system had a sampling velocity of $100 / \mathrm{s}$ and three cardiac cycles were digitised. For measurements of LV dimensions, the onset of the Q wave of the ECG was taken as LV end diastole, and end systole was taken as the point of maximal velocity of decline of LV pressure. ${ }^{14}$

LV pressure-anterior wall thickness loops were constructed using a computer software program. The following were calculated from the digitised traces of the LV anterior wall: peak anterior wall thickening and wall thinning velocities; and thickening fraction. The area of the LV pressure-wall thickness loop was taken as an index of regional external work expressed in $\mathrm{mJ} / \mathrm{cm}^{2}$ of endocardium. ${ }^{15}$ Myocardial power was derived from the product of instantaneous thickening velocity and pressure, expressed in $\mathrm{mW} / \mathrm{cm}^{2}$ of endocardium, and plotted continuously throughout the cardiac cycle. Cycle efficiency, calculated from the ratio of the LV pressure loop area to the area of the rectangle which encloses it, expressed as a percentage, represents the ratio of the useful external work done to the maximum possible by myocardium working over the same range of pressure and 
wall thickness. ${ }^{6}{ }^{13}$ Peak LV systolic pressure, LV end diastolic pressure, and the maximum rate of pressure rise $(+\mathrm{dP} / \mathrm{dt})$, and pressure decline $(-\mathrm{dP} / \mathrm{dt})$ were determined by differentiating the LV pressure trace.

Haemodynamic measurements including heart rate, mean arterial blood pressure, mean pulmonary artery pressure, cardiac index, and pulmonary capillary wedge pressure were also recorded.

\section{STATISTICAL ANALYSIS}

Results are presented as mean (SD). A one way analysis of variance with respect to time was performed for each variable. If a significant effect was demonstrated, variables at individual time points were compared using paired $t$ tests. We used unpaired $t$ tests to compare differences between groups. The $\chi^{2}$ test was used to compare non-parametric data between groups; $\mathrm{p}<0.05$ was considered significant.

\section{REPRODUCIBILITY}

This was assessed by redigitising traces from a random sample of $10 \%$ of the beats after a three month period. The variables assessed include: anterior wall thickening and thinning velocities; LV end diastolic and end systolic dimensions; cycle efficiency; and maximal LV pressure rise and decline. The root mean square difference between duplicate measurements and the values for coefficient of variation derived from the ratio of the root mean square difference and absolute value were determined.

\section{Results}

CLINICAL AND ECG DATA

All patients were successfully grafted without cardiopulmonary bypass and no patient required inotropic support or pacing postoperatively. No $\beta$ blocking drugs were given to slow the heart rate. Glyceryl trinitrate was administered at a rate of between $1-10 \mathrm{mg} / \mathrm{h}$ in all patients as is our routine practice. Mitral regurgitation was not detected on colour flow mapping pre- or postoperatively in any patient, and none showed evidence of perioperative myocardial infarction on the basis of ECG or creatine kinase levels. Three patients without collaterals developed ST segment elevation on lead V5 of the monitoring ECG, but no ECG changes were seen in those with collaterals. Major conduction abnormalities were not detected in any patient on the monitoring ECG. The clinical characteristics for patients with and without collaterals were similar. Mean age, sex distribution, presence of two vessel disease, LV ejection fraction, and coronary occlusion times were: 62 (8) $v 60$ (8) years; 4/1 v 7/2 (male/female) patients; $2 v 3$ patients; 62 (6) $v 59$ (8)\%; and 15.0 (3) v 15.8 (2) minutes, respectively, for patients with and without collaterals. Angina class according to the Canadian Cardiovascular Society was similar for those with and without collaterals; in class II, there were 3 and 5 patients, and in class III, 2 and 3 patients, respectively. Anti-anginal drug use was similar between groups and no patient had previous myocardial infarction.

EFFECT OF LEFT ANTERIOR DESCENDING ARTERY GRAFTING ON HAEMODYNAMIC AND LV PRESSURE IN PATIENTS WITH AND WITHOUT COLLATERALS Baseline heart rate, mean arterial blood pressure, cardiac index, mean pulmonary arterial, and pulmonary capillary wedge pressure were: 60 (10) $v 65$ (7) beats $/ \mathrm{min} ; 73$ (7) $v 80$ (10) $\mathrm{mm} \mathrm{Hg} ; 2.1(0.8)$ v $2.3(0.2) \mathrm{l} / \mathrm{min} / \mathrm{m}^{2} ; 18$ (4) $v 18$ (4) $\mathrm{mm} \mathrm{Hg}$, and 10 (3) $v 11$ (4) $\mathrm{mm} \mathrm{Hg}$, respectively, for patients with and without collaterals. These measurements, which were similar for both groups, did not change significantly during myocardial wall stabilisation or coronary occlusion, or in the revascularisation period in either group.

LV pressure measurements were all unaffected by wall stabilisation. During coronary occlusion, in patients without collaterals, peak $+\mathrm{dP} / \mathrm{dt}(1085$ (130) $v 1475$ (155) $\mathrm{mm} \mathrm{Hg} / \mathrm{s})$ and $-\mathrm{dP} / \mathrm{dt}(1085$ (105) v 1460 (155) $\mathrm{mm} \mathrm{Hg} /$ $\mathrm{s}, \mathrm{p}<0.01)$ decreased significantly compared to baseline. Peak -dP/dt (1100 (110) v 1460 (155) $\mathrm{mm} \mathrm{Hg} / \mathrm{s}, \mathrm{p}<0.05$ ) was still depressed 2 minutes after snare release but all measurements had returned to baseline by 10 minutes.

In patients with collaterals, coronary occlusion affected only $-\mathrm{dP} / \mathrm{dt}$, which fell (1000 (110) v 1340 (130) mm Hg/s, p < 0.05) compared to baseline. However, within 2 minutes of snare release (1235 (215) $v 1340$ (130) $\mathrm{mm} \mathrm{Hg} / \mathrm{s}$ ) it had returned to baseline values. Baseline peak systolic LV pressure and LV end diastolic pressure were 110 (15) $v 109$ (8) $\mathrm{mm} \mathrm{Hg}$ and 12 (3) v 11 (4) $\mathrm{mm} \mathrm{Hg}$, respectively, for those with and without collaterals. These measurements did not change significantly throughout the operation.

EFFECT OF GRAFTING ON LV ECHOCARDIOGRAPHIC VARIABLES IN PATIENTS WITH AND WITHOUT COLLATERALS

Myocardial wall stabilisation did not affect baseline measurements in either group. In patients without collaterals, coronary occlusion caused LV end systolic diameter to increase (3.4 (0.3) $v 2.9(0.5) \mathrm{cm}$ ), with LV end diastolic diameter remaining unchanged. Shortening fraction (24 (5) v $33(7) \%)$ and velocity (4.1

Table 1 Left ventricular anterior wall dynamics in patients without collaterals

\begin{tabular}{llllll}
\hline Variable & Baseline & $\begin{array}{l}\text { Myocardial wall } \\
\text { stabilisation }\end{array}$ & $\begin{array}{l}\text { Coronary } \\
\text { occlusion }\end{array}$ & $\begin{array}{l}2 \text { mins after snare } \\
\text { release }\end{array}$ & $\begin{array}{l}10 \text { mins after snare } \\
\text { release }\end{array}$ \\
\hline Thickening velocity $(\mathrm{cm} / \mathrm{s})$ & $2.6(0.6)$ & $2.4(0.7)$ & $1.4(0.6)^{\star}$ & $1.7(0.5)^{\star}$ & $2.6(0.5)$ \\
Thinning velocity $(\mathrm{cm} / \mathrm{s})$ & $3.0(0.6)$ & $2.9(0.8)$ & $1.4(0.5)^{\star \star}$ & $2.0(0.8)$ & $2.8(0.5)$ \\
Thickening fraction $(\%)$ & $48(16)$ & $50(10)$ & $10(6)^{\star \star}$ & $29(10)^{\star}$ & $47(13)$ \\
Peak power $\left(\mathrm{mW} / \mathrm{cm}^{2}\right)$ & $33(5)$ & $33(4)$ & $21(4)^{\star \star}$ & $25(4)^{\star}$ & $41(3)^{\star}$ \\
Regional work $\left(\mathrm{mJ} / \mathrm{cm}^{2}\right)$ & $4.6(0.6)$ & $4.8(1.0)$ & $2.2(0.8)^{\star \star}$ & $2.8(1.0)^{\star}$ & $5.9(0.5)^{\star}$ \\
Cycle efficiency $(\%)$ & $60(10)$ & $67(5)$ & $37(10)^{\star \star}$ & $48(10)^{\star}$ & $76(8)^{\star}$ \\
\hline
\end{tabular}

${ }^{\star} \mathrm{p}<0.05 v$ baseline; ${ }^{\star \star} \mathrm{p}<0.01 v$ baseline. 
Table 2 Left ventricular anterior wall dynamics in patients with collaterals

\begin{tabular}{llllll}
\hline Variable & Baseline & $\begin{array}{l}\text { Myocardial wall } \\
\text { stabilisation }\end{array}$ & $\begin{array}{l}\text { Coronary } \\
\text { occlusion }\end{array}$ & $\begin{array}{l}\text { 2 mins after snare } \\
\text { release }\end{array}$ & $\begin{array}{l}\text { 10 mins after snare } \\
\text { release }\end{array}$ \\
\hline Thickening velocity $(\mathrm{cm} / \mathrm{s})$ & $2.5(0.2)$ & $2.6(0.3)$ & $2.5(0.4)$ & $2.7(0.6)$ & $3.0(0.7)$ \\
Thinning velocity $(\mathrm{cm} / \mathrm{s})$ & $3.3(0.3)$ & $2.9(0.6)$ & $2.1(0.4)^{\star}$ & $2.7(0.6)$ & $3.3(0.7)$ \\
Thickening fraction $(\%)$ & $48(10)$ & $45(10)$ & $41(10)$ & $47(10)$ & $55(10)$ \\
Peak power $\left(\mathrm{mW} / \mathrm{cm}^{2}\right)$ & $31(4)$ & $35(4)$ & $27(4)$ & $35(5)$ & $39(3)^{\star}$ \\
Regional work $\left(\mathrm{mJ} / \mathrm{cm}^{2}\right)$ & $4.8(0.5)$ & $4.9(0.7)$ & $3.5(0.5)^{\star}$ & $5.8(0.8)$ & $6.4(0.5)^{\star \star}$ \\
Cycle efficiency $(\%)$ & $65(8)$ & $67(10)$ & $50(8)^{\star}$ & $76(6)$ & $80(5)^{\star}$ \\
\hline
\end{tabular}

${ }^{\star} \mathrm{p}<0.05 v$ baseline; ${ }^{\star \star} \mathrm{p}<0.01 v$ baseline.

(1.3) $v 6.3(1.0) \mathrm{cm} / \mathrm{s})$ thus decreased during coronary occlusion compared to baseline ( $\mathrm{p}<0.05$ for all). Within 2 minutes of snare release, all had recovered to baseline values.

In patients with collaterals, baseline LV end diastolic diameter $(4.4(0.5) \mathrm{cm})$, end systolic diameter $(3.0(0.5) \mathrm{cm})$, fractional shortening (33 (7)\%), shortening $(6.8(1.0) \mathrm{cm} / \mathrm{s})$ and lengthening $(7.0(1.0) \mathrm{cm} / \mathrm{s})$ velocities did not change significantly throughout the operation.

EFFECT OF GRAFTING ON ANTERIOR WALL DYNAMICS IN PATIENTS WITH AND WITHOUT COLLATERALS

Anterior wall measurements were unaffected by wall stabilisation in both groups (tables 1 and 2). Coronary occlusion in patients with collaterals caused a reduction in thickening fraction, thickening velocity, and thinning velocity compared to baseline along with peak power and regional work. All were still reduced 2 minutes after snare release, but by 10 minutes, thickening velocity and fraction had returned to baseline, while values of peak power (41 (3) $v 33(5) \mathrm{mJ} / \mathrm{cm}^{2}$ ) and regional work $\left(5.9(0.5) v 4.6(0.6) \mathrm{mJ} / \mathrm{cm}^{2}\right)$ were all greater than baseline $(\mathrm{p}<0.05$ for all).

In contrast, when collaterals were present, systolic measurements were unaffected. Coronary occlusion reduced thinning velocity, but not thickening velocity or fraction. Regional work (3.5 (0.5) $\left.v 4.8(0.5) \mathrm{mJ} / \mathrm{cm}^{2}\right)$ decreased during coronary occlusion compared to baseline. Asynchrony appeared, with increased wall thinning during isovolumic contraction period causing the pressure-wall thickness loop to lean further to the left in all patients. Thinning velocity, regional work, and cycle efficiency had returned to baseline values within 2 minutes of snare release, and by 10 minutes, peak power, regional work, and cycle efficiency were all above baseline values $(\mathrm{p}<0.05)$.

The configuration of LV pressure-wall thickness loops depends on abnormal wall motion during the isovolumic periods. When wall motion is coordinate, there is no change in LV dimension or wall thickness during the isovolumic periods, so the loop is rectangular and cycle efficiency is preserved. Local ischaemia causes premature wall thinning during isovolumic contraction, almost always accompanied by concomitant delayed thickening during isovolumic relaxation, giving a loop that leans to the left. ${ }^{6}$ When the primary abnormality is elsewhere in the ventricle, otherwise normal regions show reciprocal changes with premature wall thickening in the isovolumic contraction period, causing the loop to lean to the right. In the present study, both groups had asynchronous anterior wall motion at baseline resulting in reduced cycle efficiency. Eight patients without collaterals had LV pressure-wall thickness loop leaning to the left, while one patient had a loop leaning to the right. Of the patients with collaterals, four had loops leaning to the left and in one patient the loop leaned to the right. In both patients with right leaning loops, there was associated right coronary artery disease. Asynchrony worsened during coronary occlusion, with further leftward leaning of the LV pressure-wall thickness loops in all patients (fig 2). Thus cycle efficiency decreased significantly during coronary occlusion in patients without (37 (10) $v 60$ (10)\%) and with (50 (8) v 65 (8)\%) collaterals, compared to baseline $(p<0.05)$. By 10 minutes after snare release, asynchronous anterior wall motion had regressed, such that

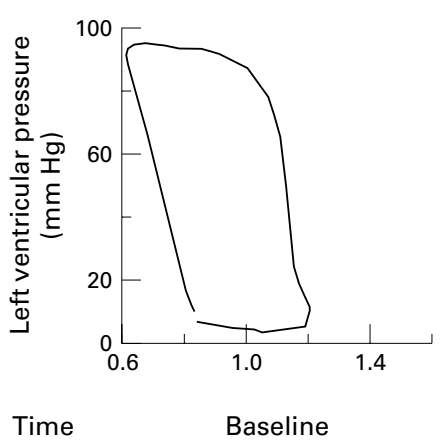

Cycle efficiency $\quad 65 \%$

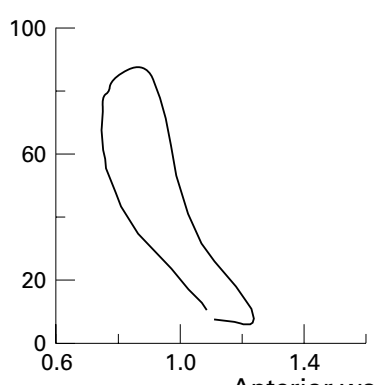

Anterior

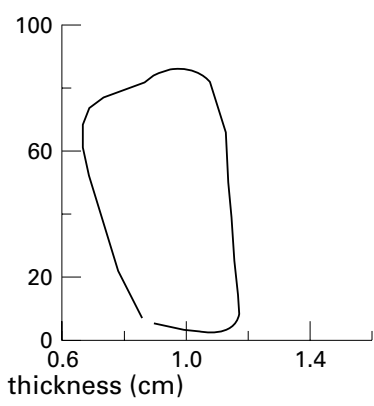

2 minutes

after snare

release

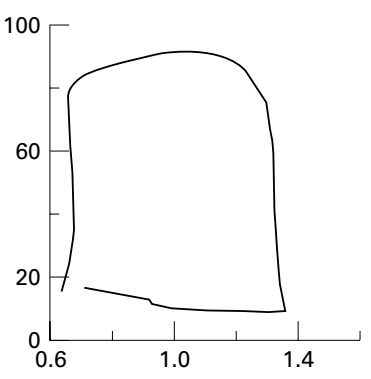

10 minutes

after snare

release

$84 \%$

Figure 2 Sequence of LV pressure-wall thickness loops in a patient without collateral supply to the left anterior descending artery, showing the loop becoming more distorted and leaning further to the left during coronary occlusion. After the coronary snare is released to re-establish blood flow, anterior wall motion becomes progressively more synchronous resulting in more rectangular loops, and greater cycle efficiency compared to baseline at 10 minutes. 
cycle efficiency had increased compared to baseline in all patients, regardless of collaterals $(\mathrm{p}<0.05)$.

\section{REPRODUCIBILITY}

The coefficient of variability of the measurements for thickening fraction, wall thickening, thinning velocities, wall thickness, and cycle efficiency ranged between $5.6 \%$ and $7.4 \%$. Myocardial power and pressure thickness loop area and the maximal rate of rise and decline in LV pressure had a variability of $6 \%$ and $8 \%$, respectively.

\section{Discussion}

Coronary artery surgery on the beating heart requires a relatively still epicardium at the site of the anastomosis, and a bloodless field, usually achieved by occluding the coronary artery proximally and distally with surgical snares. It depends on a period of coronary occlusion much longer than occurs with other established interventions such as PTCA, and concerns have been expressed about the tolerance of the myocardium to prolonged regional ischaemia in a beating and normothermic heart. ${ }^{16}{ }^{17}$ If the procedure is to be generally adopted, detailed studies are needed of the effect of prolonged ischaemia on LV function as well as on the quality of the coronary anastomosis achieved. It was the purpose of the present study to investigate detailed changes in LV function during beating heart surgery using the "Octopus" technique, and to compare the results with a previous one, using identical echocardiographic methods, of patients undergoing coronary artery surgery with cardiopulmonary bypass.

The methods used were designed to investigate regional as well as overall ventricular function, since disturbances in the time sequence of ventricular contraction are common before and after surgery in patients with chronic stable angina. In the present study, we found that the technique used to stabilise the epicardium with the application of paddles with suction cups to its surface had no effect on regional or overall ventricular function. In contrast, there were clearly defined changes in both groups during coronary occlusion, whose nature and extent depended on whether the left anterior descending artery received a collateral supply (fig 3 ). When collaterals were absent, both systolic and diastolic function of the anterior wall were depressed. Global LV function was also impaired, with a reduction in shortening fraction, and depression in peak rates of LV pressure rise and fall. In contrast, when collaterals were present, only anterior wall thinning velocity was depressed, and global LV function was unaffected. The picture with respect to regional synchrony was different, in that values were already impaired under baseline conditions, regardless of collaterals. During occlusion, asynchrony increased, particularly when collaterals were absent, but by 10 minutes after re-establishing flow, values of cycle efficiency well above baseline were recorded in both groups. The same pattern was shown by regional work.
These results can be compared with changes associated with conventional bypass surgery assessed by identical methods. ${ }^{6}$ In the previous study, control values reflecting regional asynchrony were significantly more depressed than in the present one. This difference probably reflects our selection of patients for the less invasive technique. It is not possible to study myocardial function of patients on cardiopulmonary bypass, but postoperative measures of regional LV function were effectively identical in the two studies. These were present $10 \mathrm{~min}-$ utes after re-establishing coronary flow in the present study, and at 30 minutes after the end of cardiopulmonary bypass in the previous one, which showed them to be effectively unchanged at three hours.

The requirement for coronary occlusion for beating heart surgery allows the effects of a relatively long period of myocardial ischaemia to be studied in humans. The consistent finding of left leaning pressure-wall thickness loops during coronary occlusion in both groups confirms that this loop configuration, and the disturbances of the time sequence of contraction it represents (premature thinning during isovolumic contraction and concomitant thickening during isovolumic relaxation), are caused by ischaemia. Such incoordinate wall motion impairs cycle efficiency and reduces regional work, represented by the area enclosed by the pressure-wall thickness loop. When coronary flow is restored, only cycle efficiency, along with regional work and power, improved above baseline. This suggests that measurements that reflect the efficiency of energy transfer from the myocardium to the circulation are more sensitive than simple indices of local or global ventricular function. Furthermore, when values of cycle efficiency are ranked, according to stages with increasing severity of ischaemia, a semiquantitative relation was seen, with the lowest cycle efficiency seen during coronary occlusion without collaterals, a situation expected to be associated with the most severe ischaemia. Conversely, the highest cycle efficiency was found after restoration of coronary flow with collateral supply, when ischaemia would be expected to be least.

Much shorter occlusions occurring during PTCA have been shown to depress global LV function, and to reduce regional amplitude of LV wall motion. ${ }^{18-21}$ Their effects on local synchrony have not been studied in detail by angiography. It was of interest, therefore, not only to find very similar acute effects in our patients during the occlusion itself, but also to note the effects had almost completely resolved within 10 minutes of re-establishing flow. We thus found no evidence of delayed recovery of myocardial function following restoration of flow to previously ischaemic myocardium, commonly referred to as "stunning". ${ }^{22}{ }^{23}$ Occlusion times with PTCA are considered to be too short to induce it, ${ }^{24}{ }^{25}$ but values of $15 \mathrm{~min}$ utes are well within the range used experimentally. ${ }^{23}$

Our study has limitations. We were unable to assess the presence of collaterals at the time of the operation itself, so we used data available 
No collaterals
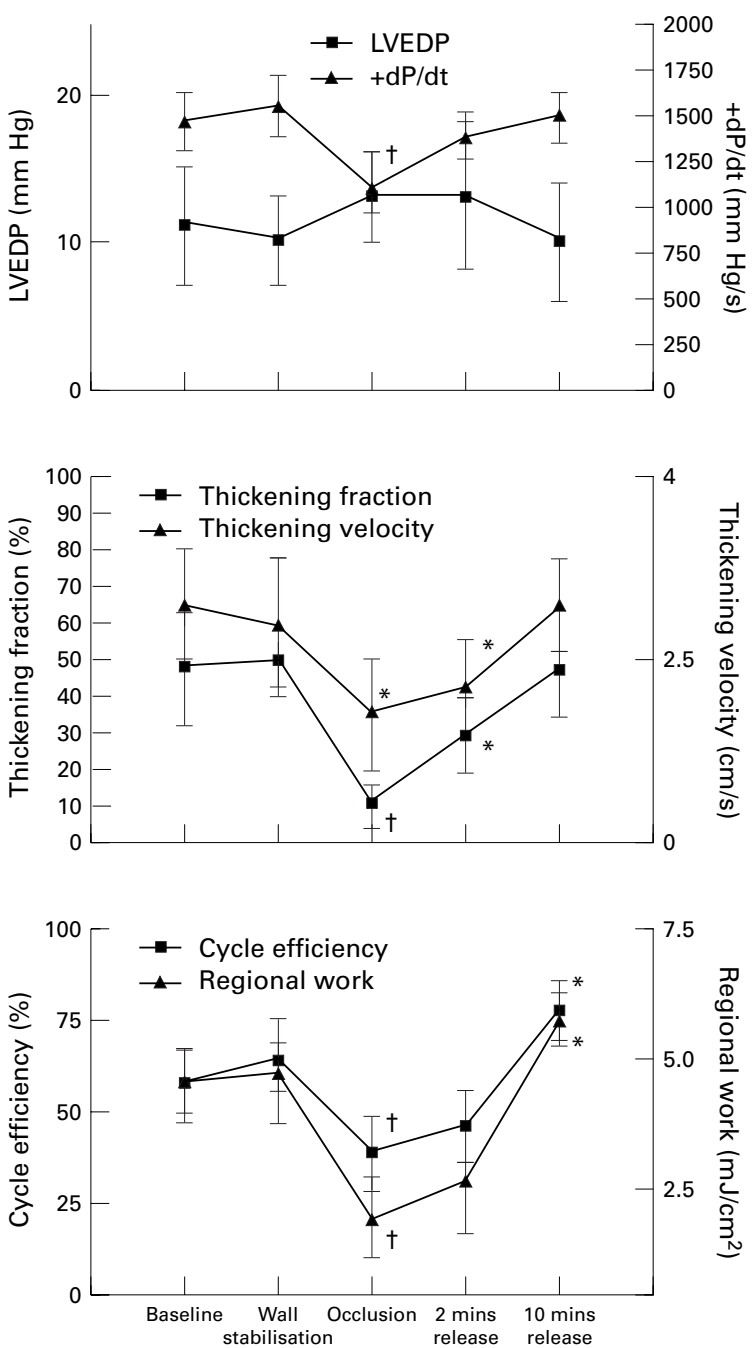

Collaterals
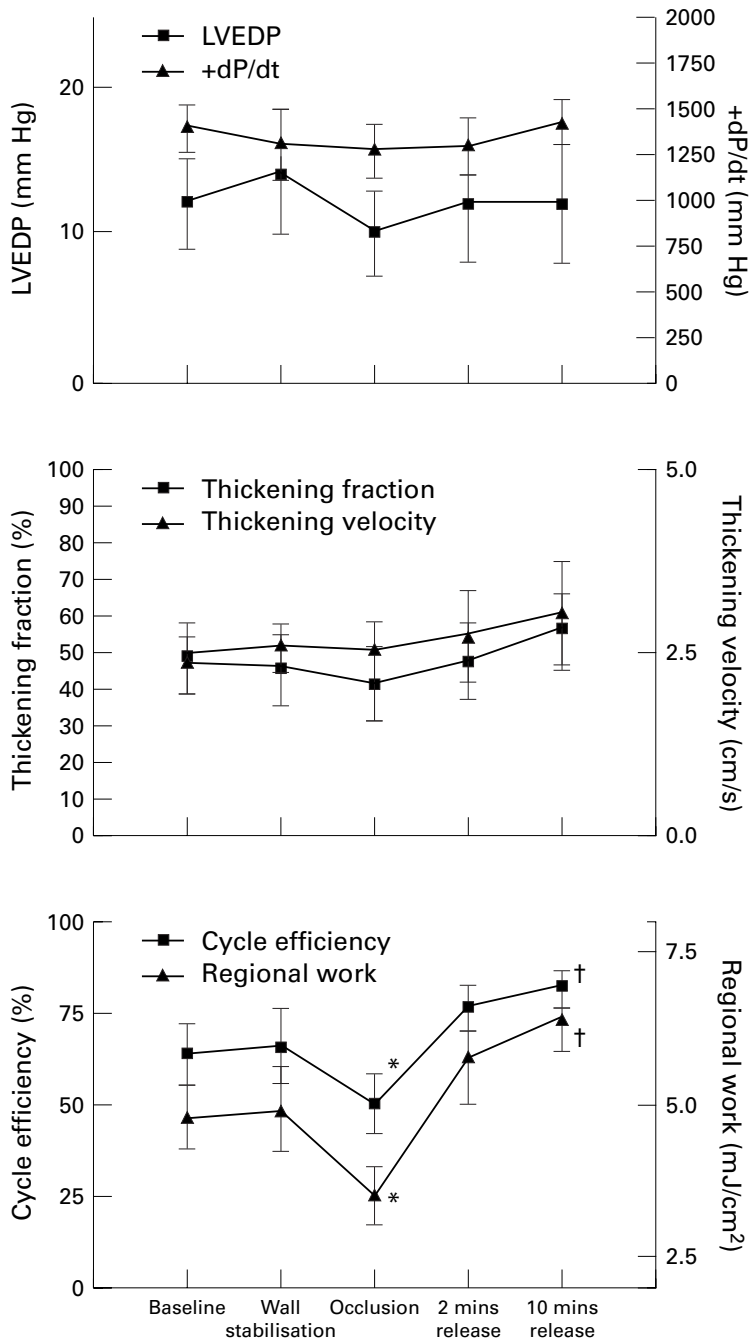

Figure 3 Graphical representation of changes in LV end diastolic pressure (LVEDP), $+d P / d t$, thickening fraction, thickening velocity, cycle efficiency, and regional work between patients with and without collaterals. ${ }_{p} p<0.05 \mathrm{v}$ baseline, $t_{p}<0.01 \mathrm{v}$ baseline. Note that changes in ventricular pressures and wall dynamics with coronary occlusion are small, particularly when collaterals are present. However, cycle efficiency and regional work decreased during coronary occlusion regardless of whether or not collaterals were present, and increased after revascularisation in both groups, to above baseline levels.

from preoperative coronary arteriography, based on a semiquantitative grading system. It is generally accepted that collaterals visualised on diagnostic angiography may not reflect accurately total collateral flow. ${ }^{26}$ Nevertheless, the clear differences we demonstrated between regions with and without angiographic collaterals indicate their presence has functional significance. The patency of the anastomoses has not yet been checked angiographically, but the consistent improvement in regional function strongly suggests that this was the case. Our failure to detect stunning may represent the compensatory effects of endogenous sympathetic stimulation or some reflex change. However, the absence of any consistent alteration in heart rate would seem to make this a rather unlikely explanation. In any case, whether stunning fails to occur, or whether it is compensated by some undefined mechanism, it does not appear to be a practical problem in the setting of beating heart surgery.

In the clinical context, our study shows that even after 15 minutes of coronary occlusion, regional $\mathrm{LV}$ function recovers to an extent identical to that seen with conventional coronary artery surgery. The finding that grafting a well collateralised vessel is better tolerated than one that is not may have implications for selection of patients for beating heart surgery, especially if this method is to be extended to patients with impaired ventricular function. ${ }^{27}$ The theoretical limitation that postoperative recovery might be delayed by some process analogous to myocardial stunning does not appear to be borne out in practice, at any rate on this group of patients with normal ejection fraction. We believe that objective measurement of local as well as overall ventricular function may allow the effects of other drugs or manoeuvres, ${ }^{17}$ aimed at attenuating the effects of ischaemia, to refine further this promising alternative approach to the treatment of coronary artery disease.

TWK is supported by a British Heart Foundation Junior Research Fellowship. 
1 Kolesov VI. Mammary artery-coronary artery anastomosis as a method of treatment of angina pectoris. 7 Thorac Caras a method of treatment of angir
diovasc Surg 1967;54:535-44.

2 Hartz RS. Minimally invasive heart surgery. Executive Committee of the Council on Cardio-Thoracic and Vascular Surgery. Circulation 1996;94:2669-70.

3 Borst C, Jansen EW, Grundeman PF. Less invasive coronary artery bypass grafting: without cardiopulmonary bypass and via reduced surgical access [editorial]. Heart 1997;77 302-3.

4 McKhann GM, Goldsborough MA, Borowicz LM Jr, et al. Cognitive outcome after coronary artery bypass: a one-year prospective study. Ann Thorac Surg 1997;63:510-15.

5 Borst C, Santamore WP, Smedira NG, et al. Minimally invasive coronary artery bypass grafting: on the beating heart and via limited access. Ann Thorac Surg 1997;63:S1-5.

6 Koh TW, Pepper JR, Gibson DG. Early changes in left ventricular anterior wall dynamics and coordination after cortricular anterior wall dynamics and coordin
onary artery surgery. Heart 1997;78:291-7.

7 Jin XY, Pepper JR, Brecker SJ, et al. Early changes in left Jin XY, Pepper JR, Brecker SJ, et al. Early changes in left ventricular function after aortic valve replacement
isolated aortic stenosis. Am f Cardiol 1994;74:1142-6.

8 Rentrop KP, Cohen M, Blanke $\mathrm{H}$, et al. Changes in collateral filling immediately following controlled coronary artery occlusion by an angioplasty balloon in man. $\mathcal{F} \mathrm{Am}$ Coll Cardiol 1985;5:587-92

9 Borst C, Jansen EW, Tulleken CA, et al. Coronary artery bypass grafting without cardiopulmonary bypass and without interruption of native coronary flow using a novel anastomosis site restraining device ("Octopus"). $\mathcal{f} \mathrm{Am}$ Coll Cardiol 1996;27:1356-64.

10 Jansen EW, Grundeman PF, Borst C, et al. Less invasive offpump CABG using a suction device for immobilization: the "Octopus" method. Eur f Cardiothorac Surg 1997;12:406 12.

11 Grundeman PF, Borst C, van Herwaarden JA, et al. Hemodynamic changes during displacement of the beating heart by the Utrecht Octopus method. Ann Thorac Surg 1997;63: b8 the Utr.

12 Grundeman PF, Borst C, van Herwaarden JA, et al. Vertical displacement of the beating heart by the Octopus tissue
stabilizer: influence on coronary flow. Ann Thorac Surg 1998;65:1348-52.

13 Gibson DG, Brown DJ. Assessment of left ventricular systolic function from simultaneous echocardiographic and pressure measurements. Br Heart 7 1976;38;8-17.

14 Abel FL. Maximal negative $\mathrm{dP} / \mathrm{dt}$ as an indicator of end systole. Am $\mathcal{F}$ Physiol 1962;240:H676-9.
15 Miyazaki S, Goto Y, Guth BD, et al. Change in regional myazaki S, Goto $\mathrm{Y}$, Guth $\mathrm{BD}$, et al. Change in regional myocardial function and external work in exercisin
with ischemia. Am $\mathcal{F}$ Physiol 1993;264:H110-16.

16 Reardon MJ, Espada R, Letsou GV, et al. Minimally invasive coronary artery surgery: a word of caution [editorial]. $\mathcal{F}$ Thorac Cardiovascr Surg 1997;114:419-20.

17 Flameng WJ. Role of myocardial protection for coronary artery bypass grafting on the beating heart. Ann Thorac Surg 1997;63:S18-22.

18 Serruys PW, Wijns W, Brand M, et al. Left ventricular performance, regional blood flow, wall motion, and lactate metabolism during transluminal angioplasty. Circulation 1984;70:25-36.

19 Hauser AM, Vellappillil G, Ramos RG, et al. Sequence of mechanical, electrocardiographic and clinical effects of repeated coronary artery occlusion in human beings: echocardiographic observations during coronary angioplasty. F Am Coll Cardiol 1985;5:193-7.

20 Henein MY, O'Sullivan C, Davies SW, et al. Effects of acute coronary occlusion and previous ischaemia injury on left ventricular wall motion in humans. Heart 1997;77:338-45.

21 Cohen M, Rentrop KP. Limitation of myocardial ischemia by collateral circulation during sudden controlled coronary artery occlusion in human subjects: a prospective study. Circulation 1986;74:469-76.

22 Braunwald E, Kloner RA. The stunned myocardium: prolonged, postischemic ventricular dysfunction. Circulation 1982;66:1146-9.

23 Bolli R. Mechanism of "myocardial stunning". Circulation 1990;82:723-38.

24 Bertrand ME, Lablanche JM, Fourier JL, et al. Left ventricular systolic and diastolic function during acute coronary artery balloon occlusion in humans. $\mathcal{F}$ Am Coll Cardiol 1988;12:341-7.

25 Carlson EB, Hinohara T, Morris KG. Recovery of systolic and diastolic left ventricular function after a 60 second coronary arterial occlusion during percutaneous transluminal angioplasty for angina pectoris. Am f Cardiol 1987;60:4606.

26 Meier B, Luethy P, Finci L, et al. Coronary wedge pressure in relation to spontaneously visible and recruitable collaterals. Circulation 1987;75:906-13.

27 Sternik L, Moshkovitz Y, Hod H, et al. Comparison of myocardial revascularization without cardiopulmonary bypass to standard open heart technique in patients with left ventricular dysfunction. Eur f Cardiothorac Surg 1997;11: 123-8. 